\title{
Venous Thromboembolism and Cancer - Still an Underestimated Problem in Medical Cancer Patients?
}

\author{
a report by \\ Mario Mandalà and Roberto Labianca
}

Unit of Medical Oncology, Riuniti di Bergamo Hospital

Thromboembolic complications represent one of the most important causes of death for cancer patients. Deep venous thrombosis (DVT), pulmonary embolism, migrant thrombophlebitis, arterial thrombosis, non-bacterial thrombotic endocarditis and disseminated intravascular coagulation (DIC) ${ }^{1}$ represent the spectrum of clinical scenarios observed in clinical practice. Disordered coagulation is encountered in up to $90 \%$ of cancer patients, although only $15 \%$ of them develop either a localised acute or chronic deep venous thrombosis or a disseminated intravascular coagulation.

Furthermore, the incidence of DVT in solid tumours is difficult to establish because most clinical studies presented in current literature show a great variability based on the type of diagnostic procedure performed (clinical alone or clinical and objective testing as venography), the most frequent tumour histotype, the medical or surgical procedure and, finally, the presence of an indwelling central venous catheter, which in itself increases the risk of thrombosis of the axillary/subclavian vein. ${ }^{2}$ Clinical conditions associated with a higher incidence of DVT (surgical interventions, immobility, chronic obstructive lung disease, cardiac failure, estrogen-progesterone use, pregnancy, puerperium) raise the already elevated risk of thromboembolism in cancer patients. From a clinical point of view, DVT of the lower limbs is the most common clinical manifestation of thromboembolic disease. Even though pancreatic adenocarcinoma has classically been associated with a higher risk of DVT, the distribution of specific cancers associated with thrombosis follows the frequency of the cancer in the general population. More recent data show that the highest incidence in men is observed in patients with lung, prostate and colorectal cancer and in women with breast, ovarian and lung cancer. ${ }^{3,4}$ Patients with cancer are clearly at high risk of developing venous thromboembolism (VTE), particularly during chemotherapy and surgery. This is aggravated by the use of venous access catheters and possibly by growth factors. ${ }^{5,6}$ No studies have been able to quantify definitively the risk of developing a DVT for each histotype and/or site of the primary tumour. In addition, although the best way to evaluate the true incidence of clinical VTE is through prospective cohort studies, most data in the literature have been derived from retrospective and prospective studies not specifically designed to evaluate the issue.

The developing of VTE is a multifactorial event involving several mechanisms. General mechanisms include inflammation due to necrosis or release of acute-phase reactants and haemodynamic disorder such as stasis. Tumourspecific mechanisms include the capacity of tumour cells to activate the coagulation cascade in several ways. The tumour cells are able to interact with host blood cells such as platelets, leukocytes and endothelial cells by releasing inflammatory cytokines - interleukin (IL)-1, tumour necrosis factor (TNF), vascular endothelial growth factor (VEGF) - or by direct cell-to-cell interactions. This results in a downregulation of anticoagulant and an upregulation of procoagulant properties of these cells, contributing to the general hypercoagulable condition of these subjects. ${ }^{7}$ Cancer cells also produce a number of procoagulant substances, including tissue factor ${ }^{8-11}$ and cancer procoagulant.12,13 Therefore, tumour tissue can directly activate the clotting cascade, leading to thrombin generation and fibrin formation. Tissue factor and other haemostatic proteins, including thrombin and fibrin, besides favouring thrombotic phenomenon, are also involved in the neoplastic dissemination and metastasis. ${ }^{14}$

\section{Venous Thromboembolism During Chemotherapy or} Hormone Therapy

The relation between VTE and chemotherapy has been most extensively investigated in patients with breast cancer. The risk of DVT in early-stage breast cancer patients under clinical control varies from 0.2 to $0.8 \%$, whereas in patients who received adjuvant therapy the risk ranges from 2 to $10 \%$, reaching $17.6 \%$ in stage IV disease. ${ }^{2}$ Levine et al. ${ }^{15}$ demonstrated that chemotherapy contributes to thrombosis in patients with breast cancer. They performed a randomised trial comparing 12 weeks of chemo-hormone therapy (using cyclophosphamide, methotrexate, fluorouracil, vincristine, prednisone, doxorubicin and tamoxifen) with 36 weeks of chemotherapy (using cyclophosphamide, methotrexate, fluorouracil, vincristine and prednisone) in patients with stage II breast cancer. Among 205 patients randomly assigned to treatment, there were 14 episodes of thrombosis (6.8\%). These 14 episodes occurred during 979 patient-months of chemotherapy; in comparison, there were no events during 2,413 patientmonths without therapy.

Tables 1 and 2 show some of the available data on DVT incidence associated with adjuvant hormone therapy and/or chemotherapy in patients with radically resected breast cancer. ${ }^{16-27}$ The limitations of these studies derive from the lack in many cases of a control population or the accurate instrumental diagnosis of DVT or pulmonary embolism. Tamoxifen raises the risk of developing a thromboembolism regardless of the presence of a neoplasm or use of chemotherapy. The risk of thromboembolism in patients taking tamoxifen as adjuvant treatment is $1-2 \%$. This risk is much higher in women undergoing chemo-endocrine therapy, reaching 13\%. ${ }^{19}$ Moreover, the risk is increased in post-menopausal women.

Mario Mandalà is Clinical Assistant in the Unit of Medical Oncology, Riuniti di Bergamo Hospital. He is a member of the European Society for Medical Oncology and a reviewer for several journals, including Annals of Oncology, Cancer Treatment Reviews, Journal of Thrombosis and Haemostasis. Dr Mandala obtained a degree in medicine and surgery in 1995 at the Catholic University in Rome and specialised in medical oncology at the Milan University in 2000.

Roberto Labianca is Head of the Unit of Medical Oncology, Riuniti di Bergamo Hospital. He is a member of several scientific societies and national representative for the American Society of Clinical Oncology and the European Organization for Research and Treatment of Cancer. He is Associate Editor of Annals of Oncology. Dr Labianca obtained his degree in medicine and surgery in 1975, and specialised in medical oncology in 1978. 
Table 1: Venous Thromboembolism Incidence in Breast Cancer Patients Who Received Adjuvant Chemotherapy for Early Breast Cancer (Stage I-II)

\begin{tabular}{|c|c|c|c|}
\hline Author(s) & Study & Regimens & VTE Incidence (\%) \\
\hline \multirow[t]{2}{*}{ Clahsen $^{16}$} & Prospective & FAC periop. & 2.1 \\
\hline & randomised & No treatment & 0.8 \\
\hline \multirow[t]{3}{*}{ Levine $^{15}$} & Prospective & CMFVP +AT & \\
\hline & randomised & (12 weeks) CMFVP & 4.9 \\
\hline & & (36 weeks) & 8.8 \\
\hline \multirow[t]{2}{*}{$\mathrm{IBCSG}^{17}$} & Prospective & CMF+AF periop. & 0.5 \\
\hline & randomised & No treatment & 0 \\
\hline \multirow[t]{3}{*}{ Weiss $^{18}$} & Prospective & CMF (2 years) & 3.5 \\
\hline & randomised & CMFVP (2 years) & 6.3 \\
\hline & & CMFbCG (2 years) & 5.4 \\
\hline \multirow[t]{2}{*}{ Pritchard $^{19}$} & Prospective & $\mathrm{CMF}+\mathrm{T}$ & 13.6 \\
\hline & randomised & $\mathrm{T}$ & 2.6 \\
\hline \multirow[t]{3}{*}{ Fisher $^{20}$} & Prospective & Tamoxifen & 1.2 \\
\hline & randomised & MTF & 4.2 \\
\hline & & CMFT & 4.5 \\
\hline \multirow[t]{2}{*}{ Tormey ${ }^{21}$} & Prospective & CMF & 0 \\
\hline & randomised & CMFPT & 3.8 \\
\hline \multirow[t]{2}{*}{$\overline{\text { Wils}^{22}}$} & Prospective & $E+T$ & 0.03 \\
\hline & randomised & $\mathrm{T}$ & 0.015 \\
\hline
\end{tabular}

Table 2: Venous Thromboembolism Incidence in Breast Cancer Patients Treated with Adjuvant Tamoxifen

\begin{tabular}{llll}
\hline Author(s) & Study & Regimens & DVT Incidence (\%) \\
\hline Cummings $^{23}$ & Prospective & Placebo & 1.2 \\
& randomised & Tamoxifen & 2.3 \\
\hline Saphner $^{24}$ & Meta-analysis & Tamoxifen & 2.3 \\
& & Placebo & 0.4 \\
\hline Rutqvist $^{25}$ & Prospective & Tamoxifen & 0.04 \\
& randomised & Placebo & 0.04 \\
\hline Fisher $^{26}$ & Prospective & tamoxifen & 0.9 \\
& randomised & Placebo & 0.2 \\
\hline McDonald $^{27}$ & Prospective & Tamoxifen & 2.8 \\
& randomised & Placebo & 2.2 \\
\hline
\end{tabular}

Saphner et al. ${ }^{24}$ showed that the frequency of thrombosis, both venous and arterial combined, was $5.4 \%$ among patients who received adjuvant therapy and $1.6 \%$ among patients without chemotherapy $(p=0.0002)$. Pre-menopausal patients who received chemotherapy and tamoxifen had significantly more venous complications than those who received chemotherapy without tamoxifen ( 2.8 versus $0.8 \%$; $p=0.03$ ). Postmenopausal patients who received tamoxifen and chemotherapy had an increased incidence of thromboembolism compared with those who received tamoxifen alone ( 8.0 versus $2.3 \% ; p=0.03$ ) or those without therapy $(8.0$ versus $0.4 \% ; p<0.0001)$. Pre-menopausal patients who received tamoxifen and chemotherapy had a $1.6 \%$ frequency of arterial thrombosis, significantly more than patients who received chemotherapy alone ( 1.6 versus $0.0 \% ; p=0.004)$.

Thromboembolism related to the addition of CMF chemotherapy to tamoxifen as adjuvant therapy in this group of women represents a relatively common and serious complication that may outweigh any benefits offered by this additional therapy. Pritchard et al. ${ }^{19}$ performed a randomised trial of tamoxifen $30 \mathrm{mg} / \mathrm{d}$ for two years versus tamoxifen plus six months of intravenous chemotherapy with CMF for postmenopausal women with involved axillary nodes and positive oestrogen receptor or progesterone receptor status following primary therapy for breast cancer. They observed one or more thromboembolic events in 48 of 353 women (13.6\%) allocated to receive tamoxifen plus CMF in comparison with five of 352 women (2.6\%) randomised to receive tamoxifen alone $(p<0.0001)$. Thromboembolic complications resulted in more days in hospital and more deaths than any other complication of therapy, including infection, in the trial.

The mechanisms by which tamoxifen could augment the risk of thrombosis could be associated with its intrinsic oestrogenic activity and reduced level of antithrombin III and Protein C. However, alterations of the laboratory parameters would not completely explain the clinically assessable risk. Mannucci et al. ${ }^{28}$ did not find any alteration of coagulation or fibrinolysis markers in non-cancer patients treated with tamoxifen (FpA, F1+2, TAT complex, D-dimers), although antithrombin and protein $C$ levels were reduced. Progesterone and its derivatives have been associated with superficial and deep thrombophlebitis in $45 \%$ of treated patients. However, the data are difficult to interpret, since most of the patients had metastatic breast cancer, a condition itself associated with thromboembolism. 29,30

\section{Central Venous Catheters and Incidence of}

\section{Thrombotic Complications}

Lack of vascular access is one of the most common problems facing oncologists today. The increased use of dose-intensive and continuous-infusion chemotherapy requires reliable vascular access, as well as frequent blood sampling to monitor potential complications of chemotherapy treatments. In addition, the increased use of supportive care measures - including intravenous antiemetics, analgesics, antibiotics, haematopoietic growth factors and hyperalimentation makes it imperative to obtain durable vascular access for an increasing number of cancer patients. Catheter-related central venous thrombosis (CR-CVT) in cancer patients has been evaluated in a number of prospective and retrospective studies. Clinical data have been recently reviewed. ${ }^{31}$

In the last two decades, two open-label randomised clinical trials have suggested a role of prophylaxis with warfarin or a low-molecularweight heparin (LMWH) in patients with a central venous catheter (CVC). Bern et al. ${ }^{32}$ described the results obtained in 82 assessable patients at risk of thrombosis associated with chronic indwelling CVC who were prospectively and randomly assigned to receive or not to receive $1 \mathrm{mg}$ fixed-dose warfarin/day, beginning three days before catheter insertion and continuing for 90 days. Venograms were obtained at the onset of thrombosis symptoms or after 90 days in the study. Among patients who completed the study, 4 of 42 who received warfarin had venogram-proven thrombosis, whereas 15 of 40 patients completing the study while not receiving warfarin had venogramproven thrombosis and 10 had symptoms of thrombosis $(p=0.001)$.

Similarly, Monreal et al. ${ }^{33}$ conducted an open randomised trial that demonstrated the efficacy of dalteparin (2500IU/day) for prophylaxis of CVC-related thrombosis. The authors demonstrated venogramproven thrombosis in $6 \%$ of treated patients versus $62 \%$ in the control group. These data have not been confirmed by more recent investigations. Four recent studies have assessed that the incidence of symptomatic CVC-related VTE is in general low - about 3-4\% - and that there is no statistically significant difference between patients undergoing and patients not undergoing prophylaxis. ${ }^{34-37}$ 
Prophylaxis of Breast Cancer Patients

\section{During Chemotherapy}

In a prospective randomised clinical trial, Levine et al. ${ }^{38}$ demonstrated that the use of warfarin at the dose of $1 \mathrm{mg} /$ day, maintaining the international normalized ratio (INR) between 1.3 and 1.9 , significantly reduced the DVT incidence in metastatic breast cancer patients who received chemotherapy. A subsequent cost-benefit analysis also showed an economic gain using low doses of warfarin to prevent major thromboembolic complications. ${ }^{39}$ Nevertheless, the event rate in this study was quite low (4.4 versus $0.6 \%$ in the study and control group, respectively); as a consequence, the prophylaxis should be tailored and individualised. There is no evidence in favour of extensive prophylaxis for cancer patients receiving chemotherapy in an outpatient setting. The final results of several ongoing studies (Topic I, II, Protecht, Prodige) will be important in order to draw conclusions in this setting.

\section{Venous Thromboembolism and Cancer - Implications for the Prognosis}

The association between venous thrombosis and tumours, although first described a century ago, remains a fascinating topic of continuous speculation in the experimental setting and a strong challenge for physicians. In the past 30 years, basic research has indicated that: tumour cells possess the capacity to activate blood coagulation by various mechanisms; this capacity parallels tumour cell malignant transformation; and fibrin formation in tumour tissues as a final product of the clotting cascade activation is involved in tumour growth and dissemination. A number of experimental studies in vitro or in animal models study the hypothesis that inhibiting blood coagulation may interfere with the progression of malignancy. Experimental and clinical data to support the hypothesis that anticoagulation may influence prognosis of cancer patients have been recently reviewed. 40,41 The VA Co-operative study \#75 reported, in a controlled, randomised trial, that warfarin may favourably modify the course of some human malignancy, including small-cell lung cancer. ${ }^{42}$ This study has been well conducted, but as the accrual of patients affected by small cell lung carcinoma was very limited (50 patients), it is hard to draw firm conclusions.
Kakkar and colleagues conducted the first randomised, placebo-controlled trial of LMWH in patients with advanced solid tumour malignancy without evidence of underlying thrombosis, with the primary objective of determining effect on survival at one year. ${ }^{43}$ The authors took into consideration previous studies that suggested that LMWH therapy may prolong survival in patients with cancer. ${ }^{44,45}$

The effectiveness of LMWH (dalteparin) 5,000Ul/die s.c. in patients with small-cell lung cancer, given in combination with chemotherapy versus chemotherapy alone, was recently evaluated by Altinbas et al. ${ }^{46}$ The results showed that at 18 weeks the overall tumour response rate was significantly higher in patients receiving chemotherapy plus LMWH compared with those receiving chemotherapy alone. The median progress free survival was also significantly prolonged with the addition of LMWH (10 versus six months; $\mathrm{p}=0.01$ ).

Two recently reported prospective, randomised, placebo-controlled trials, evaluating specifically LMWHs for survival in cancer patients, confirmed a survival benefit for patients with a good prognosis. ${ }^{43,47}$ However, the subgroup analysis performed in the Famous study was a post hoc analysis, not specified a priori. ${ }^{43}$ Recently, the survival data were examined in a post hoc analysis in patients with solid tumours and VTE who were randomly assigned to dalteparin or a coumarin derivative for six months in a multicentre, open-label, randomised, controlled trial (CLOT Study). ${ }^{48}$ The use of dalteparin relative to coumarin derivatives was associated with improved survival in patients with solid tumours who did not have metastatic disease at the time of an acute VTE event.

In conclusion, all the aforementioned data clearly indicate that knowledge of the role of the coagulation cascade in cancer development and the subsequent rational approach in clinical practice will allow us to better comprehend the genesis of cancer and to establish a correct treatment strategy for such a complication, which still represents the second leading cause of death in cancer patients.
1. Rickles FR, Levine M, Edwards RL, Cancer Metastasis Rev, 1992;11:237-48.

2. Mandala M, Ferretti GL, Cremonesi M, et al., Crit Rev Oncol Hematol, 2003;48(1):65-80.

3. Sallah S, Wan JY, Nguyen NP, Thromb Haemost, 2002;87: $575-9$.

4. Rickles FR, Levine M, Acta Hematologica, 2001;106:6-12.

5. Kwaan HC. In: Samama MM (ed.), Hypercoagulable State: Biological Aspects and Clinical Management, Boca Raton, FL: CRC Press, 1966;243-245.

6. Barbui T, Finazzi G, Grassi A, Marchioli M, Thromb Hemost, 1996;75:368-71.

7. Falanga A, Rickles FR, Thromb Res, 2001;102:215-24

8. Rao LVM, Cancer Metastasis Rev, 1992;11:249-66.

9. Callander NS, Varki N, Rao LV, Cancer, 1992;70:1194-1201.

10. Kakkar AK, Lemoine NR, Scully MF, et al., Br J Surg, 1995;82: $1101-4$.

11. Hamada K, Kuratsu J, Saitoh Y, et al., Cancer, 1996;77: 1877-83.

12. Gordon SG, Cross BA, J Clin Invest, 1981;67:1665.

13. Falanga A, Gordon SG, Biochemistry, 1985;24:5558-67.

14. Palumbo JS, Kombrinck KW, Drew AF, et al., Blood, 2000;96: 3302-9.

15. Levine MN, Gent M, Hirsh J, et al., N Engl J Med, 1988);318: 404-40.

16. Clahsen PC, van de Velde CJ, Julien JP, et al., J Clin Oncol, 1994;12:1266-71.

17. Ludwig Breast cancer study group, N Engl J Med, 1989;320:
491-6.

18. Weiss RB, Tormey DC, Holland JF, Weinberg VE, Cancer Treat Rep, 1981;65:677-9.

19. Pritchard KI, Paterson AH, Paul NA, et al., J Clin Oncol, 1996;14:2731-7.

20. Fisher B, Costantino JP, Redmond C, et al., N Engl J Med, 1989;320:479-84.

21. Tormey DC, Gray R, Taylor SG, et al., NCl Monogr, 1986;1: $75-80$.

22. Wils JA, Bliss JM, Marty M, et al., J Clin Oncol, 1999);17: 1988-98.

23. Cummings FJ, Gray R, Davis TE, et al., NCl Monogr, 1986;1: 119-23.

24. Saphner T, Tormey DC, Gray R, J Clin Oncol, 1991;9:286-94.

25. Rutqvist LE, Mattsson A, J Natl Cancer Inst, 1993;85: 1398-1406.

26. Fisher B, Dignam J, Wolmark N, et al., J Natl Cancer Inst, 1997;89:1673-82.

27. McDonald CC, Alexander FE, Whyte BW, et al., BMJ, 1995;311: 977-80.

28. Mannucci PM., Bettega D, Charntarangkul V, et al., Arch Intern Med, 1996:156:1806-10.

29. Pannuti F, Martoni A, DiMarco AR, et al., Eur J Cancer, 1979;15:593-601.

30. Tchekmedyian NS, Tait N, Abrams J, et al., Semin Oncol, 1988;15:44-9.

31. Verso M, Agnelli G, J Clin Oncol, 2003;21:3665-75.

32. Bern MM, Lokich JJ, Wallach SR, et al., Ann Intern Med,
1990;112:423-8

33. Monreal M, Alastrue A, Rull M, et al., Thromb Haemost, 1996:75(2):251-3.

34. Heaton DC, Han DY, Inder A, Intern Med J, 2002;32:84-8.

35. Verso M, Agnelli G, Bertoglio S, et al., J Clin Oncol, 2005;23: 4057-62.

36. Couban S, Goodyear M, Burnell M, et al., I Clin Oncol, 2005;23:4063-9.

37. Karthaus M, Kretzschmar A, Kroning H, et al., Ann Oncol, 2006;17:289-96.

38. Levine M, Hirsh J, Gent M, et al., Lancet, 1994;343:886-9.

39. Rajan R, Gafni A, Levine M, et al., J Clin Oncol, 1995;13; $42-46$.

40. Zacharski LR, Ornstein DL, Thromb Haemost, 1998:80:10-23.

41. Falanga A, Piccioli A, Curr Opin Pulm Med, 2005;11:403-7.

42. Zacharski LR, Henderson WG, Rickles FR, et al., Cancer, 1984:53:2046-52.

43. Kakkar AK, Levine MN, Kadziola Z, et al., J Clin Oncol, 2004;22:1944-8.

44. Green D, Hull RD, Brant R, et al., Lancet, 1992;339:1476.

45. Valentine KA, Hull RD, Pineo GF, Semin Thromb Hemost, 1997:23:173-8.

46. Altinbas M, CosKun HS, Er O, et al., J Thromb Haemost, 2004;2:1266-71.

47. Klerk CP, Smorenburg SM, Otten HM, et al., J Clin Oncol, 2005);23:2130-35.

48. Lee AY, Rickles FR, Julian JA, et al., J Clin Oncol, 2005;23: 2123-9. 